\title{
The Infant Mortality Rate in OECD Countries - Determinants and Implications
}

\author{
Viorela-Ligia VĂIDEAN ${ }^{1 *}$, Marina FERENȚ-PIPAȘ ${ }^{1}$ \\ ${ }^{1}$ Faculty of Economics and Business Administration, "Babeș-Bolyai" University Cluj-Napoca, \\ 58-60 T.Mihali Street, 400591 Cluj-Napoca, Romania \\ *)Corresponding author, e-mail: viorela.vaidean@econ.ubbcluj.ro
}

BulletinUASVM Horticulture 72(2) / 2015

Print ISSN 1843-5254, Electronic ISSN 1843-5394

DOI:10.15835/buasvmcn-hort:11484

\begin{abstract}
In the context of Romania's willingness to access the Organisation of Economic Cooperation and Development and given the rising importance of the health status improvement, the present study evaluates the determinants of the infant mortality rate indicator, as a health proxy. Supporting the better health desideratum, this study reviews the literature dealing with the estimation of infant mortality rate through econometric modelling, further examining the relationship between this dependent variable and four classes of exogenous variables: health expenditures; healthcare resources; healthcare activities and risk factors. After examining both the dependent and the independent variables, the step-wise estimation was carried out, using the Ordinary Least Squares technique, and a Fixed Effects Model as opposed to a Random Effects Model for panel data. The best model was chosen based on goodness-of-fit measures after testing for the assumptions of the multiple regression analysis. The p-value of the Student test was verified for each of the dependent variables in order to check for their significance, and the estimated coefficients proved to be significant. The results strengthen the importance of healthcare expenditures and resources on the improvement of the healthcare output. Finding optimal levels of these factors would represent a major point in the literature. Moreover, although the infant mortality rate has maintained a downward trend, it does not necessarily mean that citizens would live better or healthier.
\end{abstract}

Keywords: healthcare expenditure, infant mortality rate, number of hospital beds, panel econometrics.

\section{INTRODUCTION}

World governments have focused on improving the health status of the world population and reducing the inequalities with the help of a more efficient management of the healthcare domain. Researchers have proven that the factors that contribute to a continuous prosperity of the society are the very same factors that determine the health status of the people, and the governing policies which consider this principle are more efficient (World Health Organization, 2013). There exists a complex set of interdependent factors that contribute to maintaining one's health status, such as decent living conditions, decent incomes and work, an equitable access to education, etc.
Furthermore, maintaining one's health status leads to an increase in his/her work productivity and efficiency, a healthier ageing of population and less expenses on sick leaves and social services, thus less lost fiscal incomes. So, the health and wealth of nations may be preserved if all governing sectors would work together and approach the individual and macroeconomical determinants of the health status of the population (World Health Organization, 2013).

According to the World Health Organisation (WHO) desideratum "health for all", the universal right to health should be guaranteed. Moreover, the WHO Health 2020 document sustains the idea that healthcare performance and economic 
performance are interrelated, so resource optimization in the healthcare field is essential. The future prosperity of nations depends on their will and capacity to use new opportunities in order to strengthen the health status of their population and the wealth of future generations (World Health Organization, 2013).

The starting point of the present study is that differences in healthcare outcomes (eg. quality and length of life, infant mortality rate, equity in access, health status etc.) can be explained by differences in healthcare inputs (eg. number of physicians, hospital beds, healthcare spending etc.) as well as by differences in healthcare outputs (eg. number of patients treated, doctor consultations etc.), hypothesis which is previously confirmed by other published papers in healthcare economics and econometrics (Văidean and Ferenț-Pipaș, 2014).

Given the rising importance of the health status improvement and in the context of Romania's long declared willingness to access the OECD, the present study extends the research previously undertaken by the authors in targeting the identification of the main drivers of the healthcare system's efficiency for the OECD member countries with the final goal of comparing the results with the Romanian case.

\section{MATERIALS AND METHODS}

This research was conducted having as a starting point a wide literature review on health determinants. Considering the infant mortality rate as a health status proxy and an endogenous variable, data corresponding to nine exogenous variables were collected. In order to achieve the aims of this study, the paper uses quantitative indicators from the public OECD database. Following this aim, the paper contains a brief description of the materials and methods that the authors used in order to evaluate the health state of OECD countries though their infant mortality rate proxy. After examining both the dependent and the independent variables that explicit the infant mortality rate indicator, the step-wise estimation was carried out, using the Ordinary Least Squares technique for panel data, and a Fixed Effects Model as opposed to a Random Effects Model. Results are discussed and conclusions are drawn.

The infant mortality rate is the dependent variable and it represents the number of deaths of children under one year of age in a given year, expressed per 1,000 live births. Neonatal mortality refers to the death of children less than 28 days. These rates reflect the effect of economic and social conditions on the health of mothers and newborns but they also reflect the effectiveness of the healthcare system.

At OECD level, statistics show that approximately two in three infant deaths occur during the first four weeks (i.e. neonatal deaths), the main factors being birth defects, prematurity and other conditions arising during pregnancy. For the other one third of infant deaths (i.e. beyond one month) the principal causes lie in the Sudden Infant Death Syndrome, birth defects, infections and accidents.

The independent variables may be classified into four categories:

- Health expenditures: public healthcare spending (USD PPP/capita) and out-of-pocket payments (USD PPP/capita);

- Healthcare resources: physicians (density per 1,000 population), nurses (density per 1,000 population) and total hospital beds (per 1,000 population);

- Healthcare activities: doctors consultations (number per capita), average length of stay, ALOS, (all causes, days) and pharmaceutical consumption, antibiotics (defined daily dose);

- Risk factors: alcohol consumption, age 15+ (liters per capita).

This paper is based on an unbalanced panel econometric study conducted on various observations from a sample of 29 OECD countries observed over a period of ten years (2002-2011), excluding Estonia, Slovakia, Israel and Chile because they only entered the OECD in 2010 and by also excluding the United States of America as their predominantly private healthcare system has only recently been reformed. Each of the 29 OECD countries are part of one of the six country clusters constructed by Joumard et al (2010).

The sequential search method used was the step-wise estimation, which enables the researcher to examine the contribution of each independent variable to the regression model, firstly using the Pooled Ordinary Least Squares technique, and then a Fixed Effects Model as opposed to a Random Effects Model. The Random Effects model was chosen and the results were interpreted. The econometric software used was Gretl. 
Regressions were developed, using the infant mortality rate as an endogenous variable. In the preprocessing phase, the endogenous variable, i.e. the infant mortality rate, was examined both from the time series evolution perspective and from the distribution one in terms of meeting the assumptions of multivariate analysis. The number of missing values was of $2.07 \%$ for the infant mortality rate, thus below the $10 \%$ admissible threshold.

\section{RESULTS AND DISCUSSION}

Fig. 1 and Tab. 1 present the minimum, maximum and average infant mortality rates computed as deaths per 1,000 live births for 34 OECD countries for the 2002-2011 time period. The graph also contains data for Romania as comparison for the period under analysis. To be mentioned, the infant mortality rates are represented on the ordinate axis, while the periods are to be found on the abscissa. The minimum values range from 0.9 deaths per 1,000 live births in Iceland in 2011 to 2.8 in Japan in 2004. Luxembourg also experienced minimum infant mortality rates. To continue, maximum values were encountered in Turkey and in Mexico, values varying from 13.6 (2011) to 31.5 (2002) deaths per 1,000 live births. The gap between the countries with the lowest infant mortality rates, Iceland, Japan and Luxembourg, and the countries with the highest ones, Turkey and Mexico, is constantly narrowing from 29.3 deaths per 1,000 live births in 2002 to 12.7 deaths in 2011. Thus, at the OECD countries level it is expected, on average, 4.95 deaths per 1,000 live births with an average standard deviation of 3.43 (deaths per 1,000 live births). As it is better illustrated by the graph, the average OECD infant mortality rates are closer to the minimum than to the maximum values suggesting that most of the countries experience below the mean values. As regarding Romania, the values are above the OECD average with a constantly decreasing gap (from 11.2 deaths registered in 2002 reported per 1,000 live births to 5.5 in 2011). Overall, both in the case of the OECD countries (average) and in that of Romania it has been registered a decrease in the infant mortality rate variable for the 2002-2011 period.

Fig. 2 presents the decline in infant mortality rates for the 34 OECD countries for the period 2002-2011. To begin with, the 9 years between 2002 and 2011 saw an average decline in infant

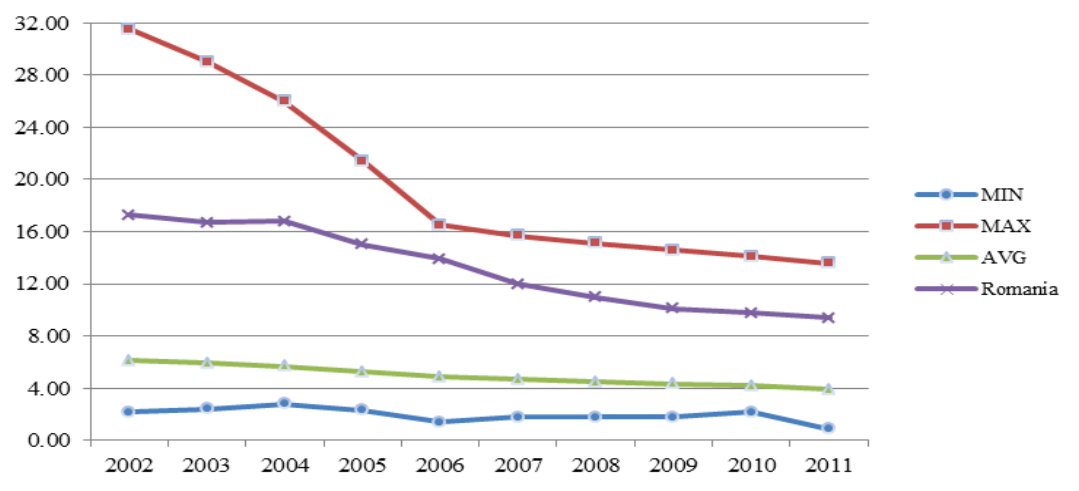

Fig. 1. Infant mortality rates in 34 OECD countries (minimum, maximum, average) and Romania, 2002-2011. Deaths per 1,000 live births

Tab. 1. Infant mortality rates' descriptive statistics in 34 OECD countries (minimum, maximum, average, standard deviation) and Romania, 2002-2011

\begin{tabular}{|l|r|r|r|r|r|r|r|r|r|r|}
\hline & $\mathbf{2 0 0 2}$ & $\mathbf{2 0 0 3}$ & $\mathbf{2 0 0 4}$ & $\mathbf{2 0 0 5}$ & $\mathbf{2 0 0 6}$ & $\mathbf{2 0 0 7}$ & $\mathbf{2 0 0 8}$ & $\mathbf{2 0 0 9}$ & $\mathbf{2 0 1 0}$ & $\mathbf{2 0 1 1}$ \\
\hline MIN & 2.200 & 2.400 & 2.800 & 2.300 & 1.400 & 1.800 & 1.800 & 1.800 & 2.200 & 0.900 \\
\hline MAX & 31.500 & 29.000 & 26.000 & 21.400 & 16.500 & 15.700 & 15.100 & 14.600 & 14.100 & 13.600 \\
\hline AVG & 6.123 & 5.936 & 5.681 & 5.279 & 4.850 & 4.679 & 4.482 & 4.361 & 4.193 & 3.906 \\
\hline STD DEV & 5.274 & 4.961 & 4.488 & 3.807 & 3.200 & 2.917 & 2.684 & 2.459 & 2.251 & 2.224 \\
\hline Romania & 17.300 & 16.700 & 16.800 & 15.000 & 13.900 & 12.000 & 11.000 & 10.100 & 9.800 & 9.400 \\
\hline
\end{tabular}


mortality rates of about 2.4 deaths in 1,000 live births. Turkey experienced the highest decrease in this period of 24.1 deaths per 1,000 live births. At a high distance, Turkey is followed by Mexico with a decline value of 5.8 deaths per 1,000 live births. On the other hand, Chile, Canada and Austria experienced a 0.1, 0.6 and 0.9 deaths decrease in this 10-year-period.

Although there may be some controversy on the appropriateness of these variables as relevant outcomes of the health system (Häkkinen and Joumard, 2007), most analyses at the system level have relied on the use of life expectancy and infant mortality to approach the outcomes of the health system and to examine a number of medical and non-medical determinants of health for a wide sample of countries in the world (RetzlaffRoberts et al., 2004). Most studies show a negative relationship between these variables and the healthcare expenditure level; the fact that some countries with a high level of health expenditure do not exhibit low levels of infant mortality suggests that more health spending is not necessarily to obtain better results. A body of research also suggests that many factors beyond the quality and efficiency of the healthcare systems - such as income inequality, the social environment and individual lifestyle and attitudes - influence infant mortality rates (Kiely et al., 1995). In addition, education has been recognized widely as a main driver of health (Ross and Wu, 1995; Cutler and Lleras-Muney, 2006). Educated people can better

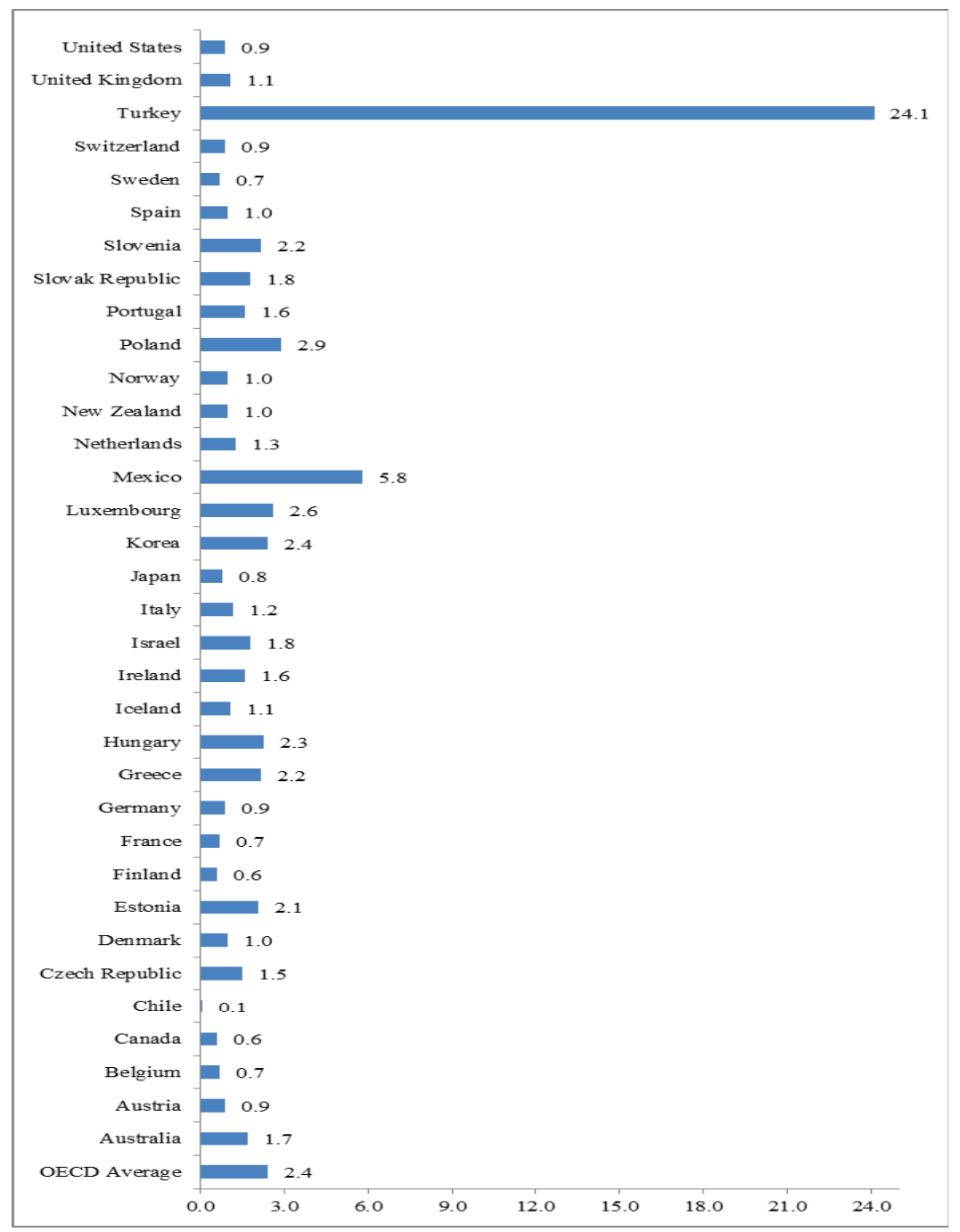

Fig. 2. Decline in infant mortality rates between 2002 and 2011 (or latest year). Data expressed in deaths per 1,000 live births for the 34 OECD countries 
interpret and evaluate information and, therefore, can make better choices to improve and preserve their health.

In analysing the normality of the endogenous variables the following empirical tools were engaged: the Jarque-Bera test, the skewness' and the kurtosis' values. To begin with, the JarqueBera's null hypothesis is that the variable is normally distributed at a 5\% significance level. The p-value was under $5 \%$ for the infant mortality rate, so the null hypothesis was rejected. Further on, the skewness was of 3.9590 and the kurtosis' value was of 18.362. In order to correct the positive skewness and the leptokurtic kurtosis of the infant mortality rate variable distribution, the log function was applied. The results improved significantly and the log (infant mortality rate) was preferred as our dependent variable.

To continue, the independent variables previously validated by other papers and used by this study may be grouped into four different categories (healthcare expenditures, healthcare associated resources, healthcare activities as well as risk factors) as previously described. The total number of missing values is below the $10 \%$ admitted threshold.

Prior assumptions were based on the literature review. Thus, a negative relationship was expected between the infant mortality rate as an endogenous variable and the following explanatory variables: public healthcare expenditures, healthcare resources and activities; a positive impact of the alcohol consumption risk factor on the infant mortality rate was expected.

All data were carefully examined and the summary statistics, using the observations for the
29 OECD countries for the ten year time period, by skipping the missing values are presented in Tab. 2.

After assessing the basic assumptions for regression analysis, the correlation coefficients' matrix was determined. The applied reasoning is that of searching for strong correlations between the endogenous variable and the exogenous ones (Tab. 3) and avoiding strong correlations between the explanatory variables. As such, it was firstly estimated the log (infant mortality rate) variable as a function of public healthcare spending per capita, the exogenous variable with the highest explicative power. Further on, additional dependent variables were introduced in the model as long as they were not correlated with the previously introduced variables and as long as they increased the Adjusted R2 of the overall model.

All the estimations were carried out using the Pooled OLS technique because it provides a baseline for comparisons with more complex estimators. Discriminating based on the goodnessof-fit measures, three models resulted (Tab. 4), and the last one was preferred.

A panel diagnosis followed for the chosen model (model 3). The panel diagnosis results are as follows:

- F test (H0: pooled OLS model is adequate, in favour of the FE alternative, at 5\% significance level); as the p-value was of0.994094 (>0.05), the null hypothesis was accepted, in favour of OLS.

- Breusch-Pagan test (H0: pooled OLS model is adequate, in favour of the REM alternative, at $5 \%$ significance level); as the p-value was of

Tab. 2. Summary statistics for the explanatory variables for the 29 OECD countries

\begin{tabular}{|c|c|c|c|c|}
\hline & Mean & Median & Minimum & Maximum \\
\hline Alcohol consumption & 9.7821 & 10.0000 & 1.2000 & 17.7000 \\
\hline Doctors' consultations & 7.0053 & 6.6000 & 2.5000 & 14.1000 \\
\hline Length of stay & 8.1366 & 7.5000 & 3.9000 & 22.2000 \\
\hline Nurses & 8.4785 & 8.7200 & 1.1000 & 16.6000 \\
\hline Pharmaceutical consumption & 20.9110 & 19.8000 & 9.8000 & 45.3000 \\
\hline Physicians & 3.0553 & 3.0800 & 1.3900 & 6.1400 \\
\hline Per capita GDP & 29881 & 30683 & 9484.2 & 73913 \\
\hline Number of hospital beds & 5.3979 & 4.8450 & 1.6700 & 14.4300 \\
\hline Out-of-the-pocket payment & 491.6700 & 475.0300 & 79.8110 & 1454.7000 \\
\hline Public healthcare spending & 2138.1000 & 2247.6000 & 256.1400 & 4812.6000 \\
\hline
\end{tabular}

Source: Authors' processing in Gretl 
$0.0195065(<0.05)$, the null hypothesis was rejected and the alternative one was accepted instead, in favour of REM.

- Hausman test (H0: REM is adequate, in favour of the FEM alternative, at $5 \%$ significance level); as the p-value was of $0.206988(>0.05)$, the null hypothesis was accepted, in favour of REM.

According to the F-test, Breusch-Pagan and Hausman tests, the REM technique was preferred. Additional variables were introduced in the model and goodness-of-fit measures among which, Akaike and Schwartz Info criterions, were taken into account in order to discriminate between the newly estimated models. Model (3) was chosen, the results being discussed in detail in what follows.
Table 5 illustrates the preffered model selected based on the criteria detailed in the Materials and Methods section. The results confirm the apriori hypothesis that differences in healthcare outcomes can be explained by differences in healthcare inputs (eg. number of physicians, hospital beds, healthcare spending etc.), the infant mortality rate being expressed as a function of public health spending, number of hospital beds and alcohol consumption.

The final regression explaining the infant mortality rate is represented by the following equation (all the estimated coefficients resulted significant at $1 \%$ threshold), Eq. 1:

$\log ($ infant_mortality_rate $)=2.66810-0.000290719$ × public_healthcare_spending $-0.0550094 \times$

Tab. 3. Correlation coefficients between the log (infant mortality rate) endogenous variable and each exogenous variable

\begin{tabular}{|c|c}
\hline $\mathbf{X i}$ & $\boldsymbol{\rho}\left(\log \left(\right.\right.$ infant mortality rate); $\left.\mathbf{X}_{\mathbf{i}}\right)$ \\
\hline Alcohol consumption & -0.3880 \\
\hline Doctors' consultations & -0.1478 \\
\hline Length of stay & -0.3233 \\
\hline Nurses & -0.5957 \\
\hline Pharmaceutical consumption & -0.0594 \\
\hline Physicians & -0.5259 \\
\hline Per capita GDP & -0.5629 \\
\hline Number of hospital beds & -0.3238 \\
\hline Out-of-the-pocket payment & -0.3137 \\
\hline Public healthcare spending & -0.6153
\end{tabular}

Source: Authors' processing in Gretl

Tab. 4. Models estimated with the Pooled OLS technique

\begin{tabular}{|c|c|c|c|}
\hline Log (Infant mortality rate) & Model (1) & Model (2) & Model (3) \\
\hline Constant & $2.08031^{* * *}$ & $2.55402^{* * *}$ & $2.80650^{* * *}$ \\
& $(0.0000)$ & $(0.0000)$ & $(0.0000)$ \\
\hline Public healthcare spending & $-0.000303^{* * *}$ & $-0.00027^{* * *}$ & $-0.000304^{* * *}$ \\
& $(0.0000)$ & $(0.0000)$ & $(0.0000)$ \\
\hline Alcohol consumption & & $-0.03627^{* * *}$ & $-0.02639^{* * *}$ \\
& & $(0.0000)$ & $(0.0005)$ \\
\hline Number of hospital beds & & & $-0.055009^{* * *}$ \\
& & & $(0.0000)$ \\
\hline $\mathbf{R}^{2}$ & 0.378604 & 0.435915 & 0.551684 \\
\hline Adjusted $\mathbf{R}^{2}$ & 0.376336 & 0.431384 & 0.545862 \\
\hline
\end{tabular}

Source: Authors' processing in Gretl

Note: Within parentheses there are the p-values. ${ }^{* * *}$ denotes $1 \%$ significance level, ${ }^{* *} 5 \%$ significance level and $* 10 \%$ significance level. 
number_of_hospital_beds - $0.0303145 \times$ alcohol consumption $+e$

where:

- $\log$ (infant_mortality_rate) - the logarithm of the infant mortality rate as a dependent variable

- public_healthcare_spending - public healthcare spending in US dollars/capita

- number_of_hospital_beds - total hospital beds per 1000 population

- alcohol consumption - alcohol consumption in liters per capita for the population aged 15 and above

- e - residual variable

All the estimated coefficients are significant at a $1 \%$ threshold, given by ***. Prior assumptions were confirmed: a negative relationship exists between infant mortality rate and the public healthcare expenditure and length of stay in healthcare units. As such, for 1 USD PPP/capita increase in the public healthcare spending in OECD countries, the infant mortality rate decreases by $0.029 \%$ on average, all other things equal; for one additional hospital bed/1,000 population in OECD countries, the infant mortality rate decreases by $5.5 \%$ on average, all other things equal. In the case of alcohol consumption, surprisingly, these results describe a negative relationship between it and the dependent variable. Still, this relationship was previously approved by the Jumard et al. (2010) working paper as well as by Cundiff (2012). As such, at a one liter per capita increase in alcohol consumption in OECD countries, the infant mortality rate would decrease by $3.03 \%$ on average, all other things equal. This issue is to be further researched from the perspective of the alcohol consumption of the pregnant women; due to lack of available data at OECD level for the present moment, the study considered the general alcohol consumption as a good proxy also given the literature in the area.

As portrayed in Fig. 3, it may be noticed that the optimal chosen model, both based on hypothesis testing and information criteria, fits the real actual values of infant mortality rates pretty well (the real data are represented with + while the data fitted by the model are represented with $x$ ). The model validaded by this study further permits the evaluation of the evolution of infant mortality rates based on the expected values of the public healthcare spending, hospital beds and alcohol consumption as explanatory variables. The originality of this paper resides in the rationality used in selecting the proper variables and interpretation of results, this study taking a new spin in the health care determinants research area.

Tab. 5. Models estimated with the REM technique Dependent variable - log (Infant Mortality Rate)

\begin{tabular}{|c|c|}
\hline & Dependent variable $-\log$ (Infant Mortality Rate) \\
\hline Public health expenditure & $-0.0002907^{* * *}$ \\
& $(7.62 \mathrm{e}-030)$ \\
\hline Alcohol consumption & $-0.0303145^{* * *}$ \\
& $(0.0002)$ \\
\hline Number of hospital beds & $-0.0550094^{* * *}$ \\
& $(9.10 \mathrm{e}-010)$ \\
\hline Constant & $2.66810^{* * *}$ \\
& $(1.04 \mathrm{e}-084)$ \\
\hline 'Within' variance & 0.105155 \\
'Between' variance & 0.0068338 \\
Breusch-Pagan test & 5.45553 \\
& $(0.0195065)$ \\
Hausman test & 4.56014 \\
& $(0.206988)$ \\
Number of observations & 206 \\
\hline
\end{tabular}

Source: Authors' processing

Note: Within parentheses there are the p-values. ${ }^{* *}$ denotes $1 \%$ significance level, ${ }^{* *} 5 \%$ significance level and $* 10 \%$ significance level. 
The cross-country differences in health status along with the most important factors explaining them are portrayed in Tab. 6. The countries splittings into groups correspond to the previous cluster analysis undertaken by Joumard et al. (2010). The values are computed as the difference between countries and the OECD average for each variable expressed in years, based on data from 2011 or latest available year. Nevertheless, the country-specific effect was computed as the difference between the exogenous variable value and the sum of the other endogenous variables.

As presented in Tab. 6, the difference between infant mortality rate in country $\mathrm{X}$ and the OECD average takes values ranging from -1.8066 deaths per 1,000 live births in Sweden to 9.69333 deaths in Mexico, thus a 12.7 deaths maximum range. From each 1,000 live births, Mexico's infant mortality rate is with 9.7 deaths higher compared to OECD average or otherwords said a child born in Mexico has 9.7 in 1,000 less chances to die in the first year after birth than the OECD average; out of these deaths, 0.002818036 are due to differences in healthcare spending and 0.53322445 are due to difference in number of hospital beds, the rest being attributed to differences in alcohol consumption and country specific effects.

At average level, the best performance in terms of infant mortality rate was registered by countries in Group 3 and the lowest one by countries in Group 5. Still, the values for countries in each group deviate a lot from the average, suggesting that no healthcare system outperforms the other in delivering cost-effective healthcare, thus there is room in all the six country clusters in improving value-for-money and no general policy recommendations can be drawn.

\section{CONCLUSION}

The current study targeted a detailed radiography of the infant mortality rate as a healthcare output, in 29 OECD countries, as a proxy for the health status of their population and an expression of the healthcare efficiency.

Current findings point out that the infant mortality rate is negatively influenced by healthcare public expenditure, number of hospital beds and surprisingly, by alcohol consumption.

Future research perspectives of the current study include developing papers having some other dependent variables, such as life expectancy at the age of 65 , possible years of life lost and/or amenable mortality rate. It would be interesting to test separately for gender differences or age groups as significant such results were obtained by other researchers. Furthermore, with respect to the used estimation techniques for panel data, potential options include dynamic panel model

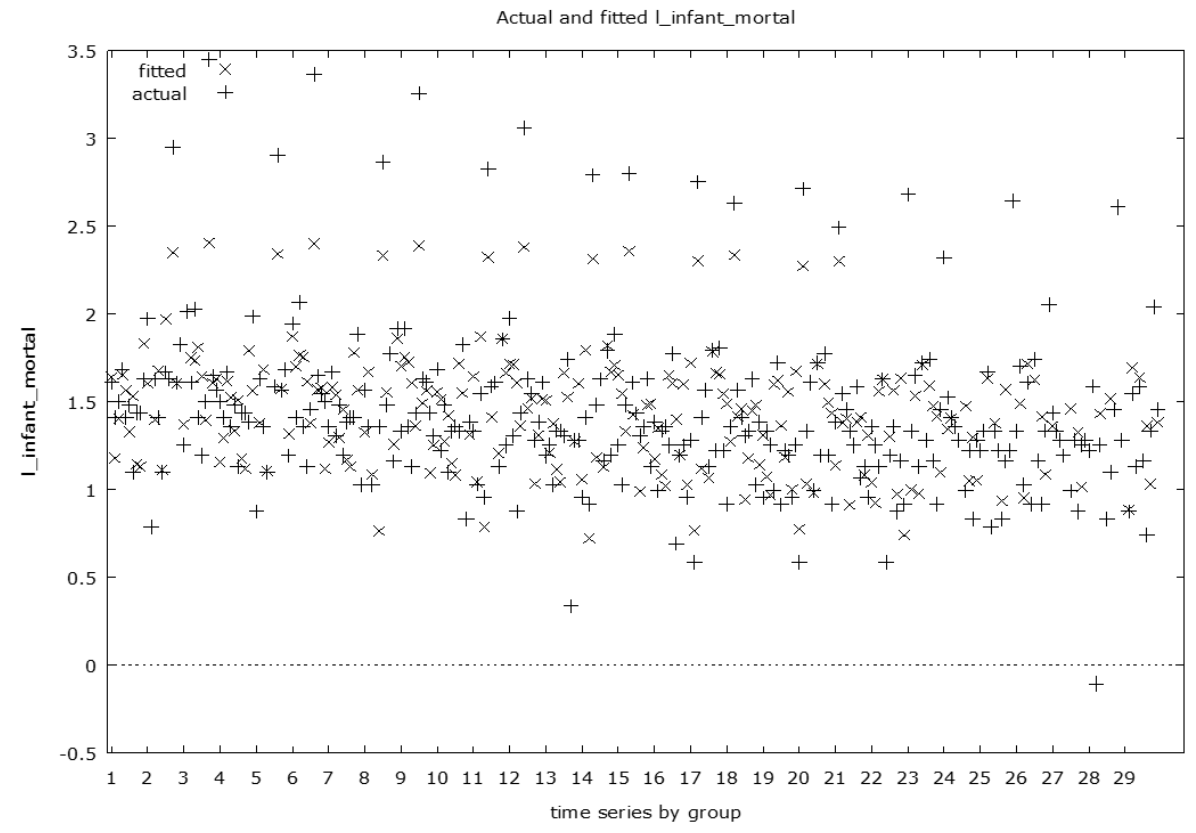

Fig. 3. Actual and fitted values of infant mortality rate with the REM Source: Authors' processing in Gretl 
Tab. 6. Contributions of main explanatory variables to cross-country differences in infant mortality rate. Differences between countries and the OECD average for each variable expressed in years, 2011 or latest available year

\begin{tabular}{|c|c|c|c|c|}
\hline \multirow[b]{2}{*}{ Country } & \multirow[b]{2}{*}{$\begin{array}{c}\text { Infant } \\
\text { mortality } \\
\text { rate }\end{array}$} & \multicolumn{3}{|c|}{ Determinants } \\
\hline & & $\begin{array}{c}\text { Public } \\
\text { healthcare } \\
\text { spending }\end{array}$ & $\begin{array}{l}\text { Number of } \\
\text { hospital beds }\end{array}$ & $\begin{array}{c}\text { Alcohol } \\
\text { consumption }\end{array}$ \\
\hline \multicolumn{5}{|c|}{ GROUP 1: private insurance for basic coverage } \\
\hline Germany & -0.30667 & 0.0000892 & 0.016869549 & 0.009296447 \\
\hline Netherlands & -0.30667 & 0.0000892 & 0.016869549 & 0.009296447 \\
\hline Slovak Republic & 0.99333 & -0.000288781 & -0.054642671 & -0.030112403 \\
\hline Switzerland & -0.10667 & 0.000031 & 0.005867669 & 0.003233547 \\
\hline \multicolumn{5}{|c|}{ GROUP 2: private insurance beyond basic coverage } \\
\hline Australia & -0.10667 & 0.000031 & 0.005867669 & 0.003233547 \\
\hline Belgium & -0.60667 & 0.000176 & 0.033372369 & 0.018390797 \\
\hline Canada & 0.99333 & -0.000288781 & -0.05464267 & -0.030112403 \\
\hline France & -0.40667 & 0.0001183 & 0.022370489 & 0.012327897 \\
\hline \multicolumn{5}{|c|}{ GROUP 3: little public insurance beyond basic coverage } \\
\hline Austria & -0.30667 & 0.0000892 & 0.016869549 & 0.009296447 \\
\hline Czech Republic & -1.20667 & 0.0003508 & 0.066378009 & 0.036579497 \\
\hline Greece & -0.50667 & 0.0001473 & 0.027871429 & 0.015359347 \\
\hline Japan & -1.60667 & 0.0004671 & 0.088381769 & 0.048705297 \\
\hline Korea & -0.90667 & 0.0002636 & 0.049875189 & 0.027485147 \\
\hline Luxembourg & 0.39333 & -0.000114349 & -0.0216371 & -0.011923703 \\
\hline \multicolumn{5}{|c|}{ GROUP 4: mostlv public insurance: wide choice among healthcare providers } \\
\hline Iceland & -3.00667 & 0.0008741 & 0.165394929 & 0.091145597 \\
\hline Sweden & -1.80667 & 0.0005252 & 0.099383649 & 0.054768197 \\
\hline Turkey & 3.79333 & -0.001102794 & -0.20866899 & -0.114993003 \\
\hline \multicolumn{5}{|c|}{ GROUP 5: mostly public insurance; limited choice among healthcare providers } \\
\hline Denmark & -0.30667 & 0.0000892 & 0.016869549 & 0.009296447 \\
\hline Finland & -1.50667 & 0.0004381 & 0.082880829 & 0.045673847 \\
\hline Mexico & 9.69333 & -0.002818036 & -0.53322445 & -0.293848553 \\
\hline Portugal & -0.80667 & 0.0002346 & 0.044374249 & 0.024453697 \\
\hline Spain & -0.70667 & 0.0002055 & 0.038873309 & 0.021422247 \\
\hline \multicolumn{5}{|c|}{ GROUP 6: mostly public insurance; limited over-the-basic coverage } \\
\hline Hungary & 0.99333 & -0.000288781 & -0.05464267 & -0.030112403 \\
\hline Ireland & -0.40667 & 0.0001183 & 0.022370489 & 0.012327897 \\
\hline Italy & -0.50667 & 0.0001473 & 0.027871429 & 0.015359347 \\
\hline New Zeeland & 1.59333 & -0.000463212 & -0.08764831 & -0.048301103 \\
\hline Norway & -1.50667 & 0.0004381 & 0.082880829 & -0.048301103 \\
\hline Poland & 0.79333 & -0.000230637 & -0.04364079 & -0.024049503 \\
\hline United Kingdom & 0.39333 & -0.000114349 & -0.02163703 & -0.011923703 \\
\hline \multicolumn{5}{|c|}{ Memarandum items } \\
\hline Maximum range & 12.7 & 0.004 & 0.7 & 0.4 \\
\hline $\begin{array}{c}\text { Estimated } \\
\text { coefficients }\end{array}$ & & $\begin{array}{c}-0.0290719 \% \\
* * *\end{array}$ & $-5.50094 \% * * *$ & $-3.03145 \% * * *$ \\
\hline
\end{tabular}

Source: Authors' processing

and data envelopment analysis. Also, expanding the analysis on a larger data set, by including Romania as well, represents a major goal for future studies.
All in all, although the infant mortality rate has maintained a downward trend, if we are expected to live longer, it does not necessarily mean that we would live better or healthier. So a 
great importance has to be given to improvements in individual life style and promoting healthier living.

\section{REFERENCES}

1. Cundiff K.R. (2012), Infant Mortality, Health Care, and Economics, Annals of the „Constantin Brâncuşi” University of Târgu Jiu, Economy Series, Issue 3/2012, Târgu Jiu, Romania

2. Cutler D.M., Lleras-Muney A. (2006), Education and Health: Evaluating Theories and Evidence, NBER Working paper, Published: House, J., R. Schoeni, G. Kaplan, and H. Pollack (eds.) Making Americans Healthier: Social and Economic Policy as Health Policy. New York: Russell Sage Foundation, 2008.

3. Häkkinen, U. and I. Joumard (2007), "Cross-Country Analysis of Efficiency in OECD Health Care Sectors: Options for Research", OECD Economics Department Working Papers, No. 554, OECD Publishing, Paris.

4. http://dx.doi.org/10.1787/178861806081

5. Joumard I., André C. and Nicq C. (2010), Health Care Systems: Efficiency and Institutions, OECD Economics
Department Working Papers, No. 769, OECD Publishing, Paris CEDEX, France. Also available online at: http:// dx.doi.org/10.1787/5kmfp51f5f9t-en

6. Kiely et al (1995) cited in "Infant mortality", Health at a Glance 2009: OECD.

7. Retzlaff-Roberts D., Chang C.F., Rubin R.M. (2004), Technical efficiency in the use of health care resources: a comparison of OECD countries, Health Policy, vol. 69, no. 1: 55-72.

8. Ross C.E., Wu C.L (1995), The Links Between Education and Health, American Sociological Review, Vol. 60, No. 5: 719-745, Published by: American Sociological Association, Stable URL: http://www.jstor.org/stable/2096319

9. Văidean V.L., Ferenț-Pipaș M. (2014), Health and Healthcare Indicators - Panel Data Analysis for OECD Countries, International Journal of Academic Research in Business and Social Sciences, Vol. 4, Issue 8, pp. 76-99

10. World Health Organization (2013), Health 2020: the European policy for health and well-being, World Health Organization Publishing House 